\title{
Synthesis of PI Controller with a Simple Set- Point Filter for Unstable First-Order Time Delay Processes and Integral plus Time Delay Plant
}

\author{
Radmila Gerov $^{1}$, Zoran Jovanovic ${ }^{2}$ \\ ${ }^{1}$ School of Agriculture with a student's dormitory Rajko Bosnic, \\ Bukovo, 19300 Negotin, Serbia \\ ${ }^{2}$ Department of Control Systems, University of Nis, Faculty of Electronic Engineering, \\ Aleksandra Medvedeva 14, 18000 Nis, Serbia \\ gerov@ptt.rs
}

\begin{abstract}
The paper describes PI controllers tuning for unstable first order time delay processes and integral plus time delay plant. The suggested method for designing a PI controller is based on the pole assignment method. Conditions for selecting the PI controller parameters in the function of the desired poles and parameters of the plant are met by using the features of the Lambert $W$ function. The system stability in feedback is guaranteed by selecting the desired poles of the predefined range. The determined scope for pole selection includes the condition that this controller operates without integral gain, merely as proportional. The overshoot is reduced by using the simple first-order set-point filter. The manner of selecting the initial matrix which is used in a LambertW DDE toolbox has been proposed. The illustrations of the simulation have been provided. Performances of the system regulated with a suggested PI controller are compared with the results received from other methods wherefrom it may be seen that this method yields better results in terms of the system settling time, rise time and IAE, ISE for set-point and good results in term of IAE, ISE for load disturbance and for the robustness on the uncertain changes expressed by the process parameter change of $10 \%$.
\end{abstract}

Index Terms-Pole assignment; PI controllers; Time delay; Unstable FOPTD processes; Integral plus time delay plant.

\section{INTRODUCTION}

Proportional-integral-differential (PID) or Proportionalintegral (PI) controllers have been used for the regulation of the processes in the industry for years now [1]. It is welldocumented that they are used with time-delay processes, too, and that the presence of time-delay in continual systems renders the application of the traditional methods of analysis and the projection within a time and frequency area largely complex. A number of different methods of parameter selection for these controllers, which can be found in different reference books or scientific papers, in [2]-[10], inter alia, have been developed over the years. The identification and control of unstable time delay processes has been notably examined in numerous studies among

Manuscript received 18 December, 2017; accepted 5 March, 2018.

This paper was realized as a part of the projects III 43007 and TR 35005, funded by the Ministry of Education, Science and Technological Development of the Republic of Serbia. which are the papers [11]-[13].

In this study, the synthesis of the PI controller was performed by using a pole placement method with the features of Lambert $\mathrm{W}$ function described in [14] and [15]. A characteristic system equation was solved by using the matrix Lambert $\mathrm{W}$ function described in [16], [17] by following exceptional cases during the application of the matrix Lambert $\mathrm{W}$ function explained in the stability analysis in [18].

The proportional and integral PI controller gain is provided in the function of the desired poles and parameters of the integral plus time delay plant (IPTD) and unstable fist-order process with time-delay (UFOPDT). Boundary conditions for the selection of the desired conjugatecomplex or real poles have been set, and they comprise the condition for the controller to operate as a proportional controller. The illustrative examples of the response of the PI control of UFOPDT for different values of the desired poles and the confirmation of the boundary conditions were received via simulation.

Considering that during the application of the LambertW_DDE toolbox, the problem may arise by inadequate selection of the initial matrix $Q$, the method of its selection has been put forward (Yi, Duan, Nelson, and Ulsoy (2012) in the function of the desired poles, which solves the problem.

It is well known that during the regulation with UFOPDT helped by a PI controller there is a great overshoot, and that the overshoot cannot be reduced by adding a set-point firstorder filter. For different values of the time constant of the simple set-point filter, in the function of the relation of the proportional and integral part of the controller, a response received by simulation has been given.

Performances of the system regulated with a PI controller received through the suggested projection method have been compared for IPTD plant with the results received from the methods given in [8], [9], while for UFOPTD plant with the result in [11], wherefrom it may be seen that this method yields better results.

The paper is organized in the following way: Chapter II gives a design of the PI controller, whereby in the first part 
there is a short description of the Lambert $\mathrm{W}$ functions, while in the second part a procedure for solving the characteristic equation has been given, and in the third, the conditions and the methods of selection of the dominant poles, PI controller parameters and initial matrix Q parameters, have been provided. In the third part, the selection of the desired poles for time delay for an IPDT plant is represented which is used for the most optimal results both for set-point tracking and for the disturbance reaction. In the fourth part of chapter II, two methods of synthesis are shown. In Chapter III, the results received by simulation for UFOPTD have been shown. In the first part, the results of the response in the presence of the disturbance for different pole values are given, IAE of the output, Overshoot of the output, Total variation of the input, for the set-point and load disturbance. The second part illustrates the results received in simulation by using a set-point firstorder filter for different values of its time constant, and in the third section, there is a confirmation of the boundary condition for the selection of the imaginary part of the desired poles has been presented by using a simulation. In chapter IV, the analysis received by controlling IPDT and UFOPTD processes on the suggested way is given in parallel with the results received with other methods. Chapter V provides a conclusion and suggestion for a further analysis.

\section{THE PROPOSED METHOD}

\section{A. Lambert W Function}

Lambert $\mathrm{W}$ function $W(z)$ is the solution of the equation

$$
W(z) e^{W(z)}=z
$$

where $z \in C$. If $z$ belongs to a set of complex numbers $C$, the function has an infinite number of solutions, as well as an infinite number of branches $W_{k}(z)$ where $k \epsilon(-\infty, \infty)$. Only $W_{0}(z)$-principal branch for $k=0$, and branches $W_{-l}(z)$ for $k=-1$, take real values (Fig. 1).

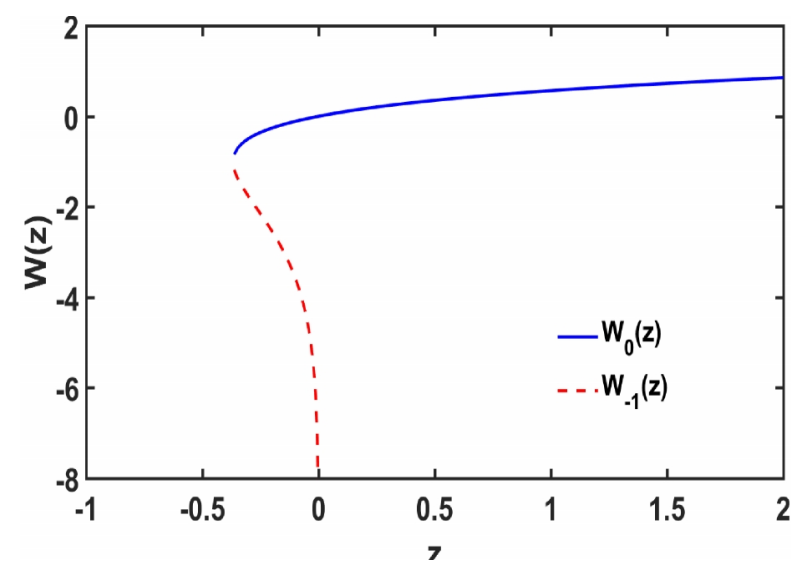

Fig. 1. Two main branches of the LambertW function for $z \in R$.

$W_{0}(z)$ is analytic at the point of zero, which ensues from the Lagrange's inversion theorem which provides the series expansion with the radius of convergence $e^{-1}$

$$
W_{0}(z)=\sum_{n=1}^{\infty} \frac{(-n)^{n-1}}{n !} z^{n}
$$

A differential of the Lambert $\mathrm{W}$ functions was obtained by applying the Ranger's technique

$$
W^{\prime}(z)=\frac{W(z)}{z(1+W(z))},
$$

where $z \neq 0$. A more detailed explanation of the method of solution (1) and the branch range $\mathrm{Wk}(\mathrm{z})$ can be read in Corless, Gonnet, Hare, Jeffrey and Knuth (1996).

\section{B. Synthesis of PI Controller}

Let the processes with time delay be described by transfer function

$$
G_{p}(s)=\frac{K}{T s-a} e^{-\theta s}
$$

where $K$ is the plants' gain, $T$ is the time constant, $\theta$ is the time delay and $a$ is a coefficient.

If $a=1$, the transfer function (4) becomes the transfer function of the UFOPTD, while the transfer function of the IPTD can be received from (4) for $a=0$ and $T=1$.

These processes can be suitably controlled by using a PI controller, Fig. 2. where $K_{p}$ and $K_{i}$ are gain coefficient of the proportional and integral part of the controller, with the transfer function

$$
G_{c}(s)=K_{p}+\frac{K_{i}}{s},
$$

which in the time domain corresponds to

$$
u(t)=K_{p} e(t)+K_{i} \int_{0}^{t} e(t) d t
$$

where $e(t)=r(t)-y(t)$ and $y(t)$ is the output signal of the coupled system with the negative feedback of the unit, $u(t)$ is a control signal, and $r(t)$ is a reference signal.

In a time domain, the feedback system can be described through second-order Delay-Differential Equations (DDE)

$$
\frac{d x}{d t}=A x(t)+A_{d} x(t-\theta),
$$

with belonging matrices:

$$
\left\{\begin{array}{l}
x=\left(\begin{array}{l}
x_{1} \\
x_{2}
\end{array}\right), \\
A=\left(\begin{array}{ll}
0 & 1 \\
0 & \frac{a}{T}
\end{array}\right), \\
A_{d}=\left(\begin{array}{cc}
0 & 0 \\
-\frac{K K_{i}}{T} & -\frac{K K_{p}}{T}
\end{array}\right) .
\end{array}\right.
$$

The solution of the characteristic system equation

$$
S_{k}-A-A_{d} e^{-\theta S_{k}}=0
$$


where $S_{k} \epsilon C^{2 x 2}$, is received by translating (9) into Lambert $\mathrm{W}$ form

$$
\theta\left(S_{k}-A\right) e^{\theta\left(S_{k}-A\right)}=A_{d} \theta Q_{k}
$$

whereby the unknown matrix $Q_{k} \epsilon C^{2 x 2}$ which needs to satisfy

$$
W\left(A_{d} \theta Q_{k}\right) e^{\left(W\left(A_{d} \theta Q_{k}\right)+A \theta\right)}=A_{d} \theta .
$$

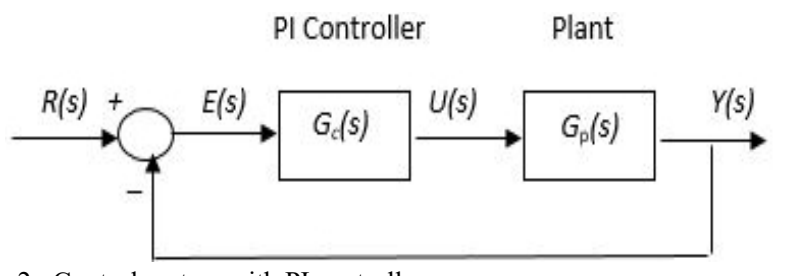

Fig. 2. Control system with PI controller.

A generic form of the solution of the characteristic equation (9) is

$$
S_{k}=\frac{1}{\theta} W_{k}\left(A_{d} \theta Q_{k}\right)+A,
$$

where $k$ denotes a Lambert W function branch.

By simultaneously solving (11) and (12) for the desired poles, PI controller parameters are obtained.

\section{Boundary Range for Selection of Controller Poles and Parameters}

Let the desired poles $\lambda_{1 / 2}=\operatorname{Re}\{\lambda\} \pm j \operatorname{Im}\{\lambda\}$ be conjugatecomplex and let the unknown matrix be

$$
Q_{k}=\left(\begin{array}{ll}
q_{11} & q_{12} \\
q_{21} & q_{22}
\end{array}\right) \text {. }
$$

The generic solution form (12) of the characteristic system equation (9) can be presented in the form of

$$
S_{k}=\left(\begin{array}{cc}
0 & 1 \\
-\lambda_{1} \lambda_{2} & \lambda_{1}+\lambda_{2}
\end{array}\right) .
$$

Let

$$
M=\left(\begin{array}{cc}
0 & 0 \\
m_{21} & m_{22}
\end{array}\right)=A_{d} \theta Q .
$$

From (10) and (15) it transpires that:

$$
\begin{aligned}
& \left(\begin{array}{cc}
0 & 0 \\
\frac{m_{21}}{m_{22}} w_{k}\left(m_{22}\right) & w_{k}\left(m_{22}\right)
\end{array}\right)= \\
& =\left(\begin{array}{cc}
0 & 0 \\
-\theta \lambda_{1} \lambda_{2} & \theta\left(\lambda_{1}+\lambda_{2}-\frac{a}{T}\right)
\end{array}\right) .
\end{aligned}
$$

It can be noticed from (16) that $w_{k}\left(m_{22}\right)<0$ and $w_{k}\left(m_{22}\right) \epsilon$ $R$, considering that due to stability the condition $\operatorname{Re}\{\lambda\}<0$ needs to be fulfilled. Depending on the value of $w_{k}\left(m_{22}\right)$, the same corresponds to the branch $k=0$ for $-1<w_{k}\left(m_{22}\right)<0$ or the branch $k=-1$ if $w_{k}\left(m_{22}\right)<-1$. Taking into consideration that the principal branch $k=0$, from (16) and the stability conditions, it follows that the real part of the desired conjugate-complex pole can be selected within the boundaries

$$
\frac{1}{2}\left(\frac{a}{T}-\frac{1}{\theta}\right) \leq R_{e}\{\lambda\} \leq 0
$$

For the selected $\operatorname{Re}\{\lambda\}$, the value of the desired imaginary conjugate complex pole is received by solving

$$
\tan \left(I_{m}\{\lambda\}\right) \leq \frac{I_{m}\{\lambda\}}{a T^{-1}-R_{e}\{\lambda\}}
$$

The received value $\operatorname{Im}\{\lambda\}$ represents a boundary condition of the existence of the integral amplification coefficient of the PI controller, which can be illustrated.

By replacing (8) and (16) with (11), and with a mathematical operation, formulas for calculation of the gain of the proportional and integral part of the PI controller in the function of the desired poles and UFOPDT and IPTD plant parameters are received:

$$
\begin{array}{r}
K_{p}=\frac{T}{K\left(\lambda_{1}-\lambda_{2}\right)}\left(\lambda_{2}\left(\lambda_{2}-\frac{a}{T}\right) e^{\theta \lambda_{2}}-\lambda_{1}\left(\lambda_{1}-\frac{a}{T}\right) e^{\theta \lambda_{1}}\right), \\
K_{i}=\frac{T \lambda_{1} \lambda_{2}}{K\left(\lambda_{1}-\lambda_{2}\right)}\left(\left(\lambda_{1}-\frac{a}{T}\right) e^{\theta \lambda_{1}}-\left(\lambda_{2}-\frac{a}{T}\right) e^{\theta \lambda_{2}}\right) .
\end{array}
$$

In this way, the controller parameters are received directly without using LambertW_DDE toolbox for whose application it is sometimes very difficult to determine the initial matrix $Q$.

Considering that there is an infinite number of matrices $Q$ (13) which can satisfy (11) and (12), we may, without the influence on the generality loss, take $q_{11}=q_{12}=1$. By replacing (8) and (13) with (15), then by applying (16), and with a mathematical operation on the received formulas, by using a definition of the Lambert $\mathrm{W}$ function, what is received is:

$$
\left\{\begin{array}{l}
q_{21}=\frac{1}{K_{p}}\left(\frac{\lambda_{1} \lambda_{2} T}{K} e^{\theta\left(\lambda_{1}+\lambda_{2}-\frac{a}{T}\right)}-K_{i}\right), \\
q_{22}=-\frac{1}{K_{p}}\left(\frac{T}{K}\left(\lambda_{1}+\lambda_{2}-\frac{a}{T}\right) e^{\theta\left(\lambda_{1}+\lambda_{2}-\frac{a}{T}\right)}+K_{i}\right) .
\end{array}\right.
$$

By replacing (19) and (20) with (21) the initial matrix coefficients $Q_{\text {initial }}$ in the function of the desired poles and UFOPDT parameters are received. Defining of the initial matrix in this way significantly alleviates the application of the LambertW_DDE toolbox for finding for example the rest of the poles for branches $k= \pm 1, \pm 2, \pm 3 \ldots$

Let the desired poles be $\lambda_{1}=\operatorname{Re}\left\{\lambda_{1}\right\}+j 0$ i $\lambda_{2}=\operatorname{Re}\left\{\lambda_{2}\right\}+$ $j 0$, i.e. let the both poles be real. Considering that for the principal branch of the Lambert $\mathrm{W}$ function $k=0$ stands that $-1<w_{k}\left(m_{22}\right)<0$, from (16) what follows is 


$$
-1<\theta\left(\lambda_{1}+\lambda_{2}-\frac{a}{T}\right)<0
$$

From (22) and the stability conditions saying that the both poles must be in the left semi-plane of the complex $s$-plane, boundary conditions for the selection of the desired real poles transpire

$$
\frac{a}{T}-\frac{1}{\theta}<\lambda_{1}+\lambda_{2}<0
$$

The proportional and integral PI controller gain is received in case of real poles, too, by applying (19) and (20), and the initial matrix $Q$ is received with (21).

Considering that (17) and (23) it can be inferred that the suggested method can be used only if the time constant of the UFOPDT process is greater than the time delay $T>\theta$.

By analysing different IPDT plants, it has been determined that good results are received by using the boundary condition for the real part of the pole (17), that is, by selecting the desired pole values

$$
\lambda_{1 / 2}=\frac{-0.5 \pm 0.25 j}{\theta}
$$

By replacing $a=0$ and $T=1$ in (19) and (20) for the selected poles (24), the gain of the proportional and integral part of the PI controller for IPDT plant are received respectively from:

$$
\begin{aligned}
K_{p} & =\frac{1}{K\left(\lambda_{1}-\lambda_{2}\right)}\left(\lambda_{2}{ }^{2} e^{\theta \lambda_{2}}-\lambda_{1}^{2} e^{\theta \lambda_{1}}\right), \\
K_{i} & =\frac{\lambda_{1} \lambda_{2}}{K\left(\lambda_{1}-\lambda_{2}\right)}\left(\lambda_{1} e^{\theta \lambda_{1}}-\lambda_{2} e^{\theta \lambda_{2}}\right) .
\end{aligned}
$$

\section{Synthesis of Set-Point Filter}

For eliminating the overshoot, which occurs when using the PI controller at the considered processes, can be added to the set-point filter of the first order transfer function $G_{f}(s)$, as shown in the Fig. 3.

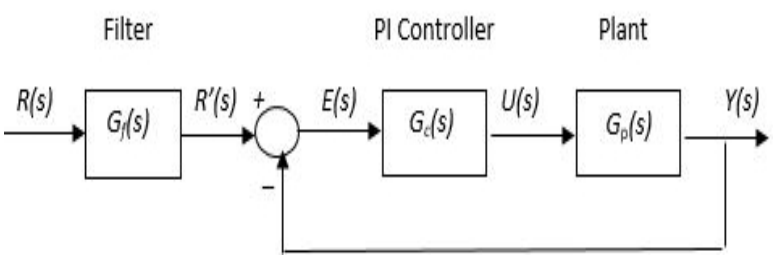

Fig. 3. Control system with PI controller and set-point filter.

Basic form of the transfer function of the filter, where $b$ of a set-point weight coefficient is

$$
G_{f}(s)=\frac{b \frac{K_{p}}{K_{i}} s+1}{\frac{K_{p}}{K_{i}} s+1}
$$

From the equation (27) it can be noticed that by implementing the filter for $b=0$, shortening the denominator of the transfer function of the filter with the zero feedback transfer function of the PI controller and plant, while the system shown in Fig. 3, for $b=1$, behaves in the same way as the system shown in Fig. 2, that is, there is a classic control of the plant with the PI controller.

Setting the filter is done by setting the set-point weight of the coefficient $b$, which usually ranges between 0.2 and 0.5 . At IPDT plant good results are obtained by $b=0.3-0.4$.

For a UFOPTD process, a set-point filter can also have transfer functions

$$
G_{f}(s)=\frac{1}{T_{f} s+1},
$$

where $T_{f}=n \frac{K_{p}}{K_{i}}, T_{f}$ is a time constant of the filter which can be expressed as the function of the gain of the proportional and integral part of the controller, where $n \epsilon$ $\mathrm{R}+$.

\section{RESULTS RECEIVED BY SIMULATION FOR UFOPTD}

\section{A. Responses for a PI-Control of UFOPDT in the Presence} of the Disturbance for Different Values of the Desired Pole

A UFOPTD process has been evaluated, with parameters $K=1, T=5, \theta=1$, from Shamsuzzoha and Skogestad (2010).

Let the desired poles be conjugate complex. By applying (17) the range for selecting a real part of the desired pole is received

$$
-0.4 \leq R_{e}\{\lambda\} \leq 0
$$

Let $\operatorname{Re}\{\lambda\}=-0.35$. By applying (18) we find a boundary condition for selecting an imaginary part of the desired pole $\operatorname{Im}\{\lambda\}<1.1112$.

Responses for PI-control of the unstable first-order time delay process where a set-point change at $t=0$, load disturbance of magnitude 1 at $t=40$, is given in Fig. 4 .

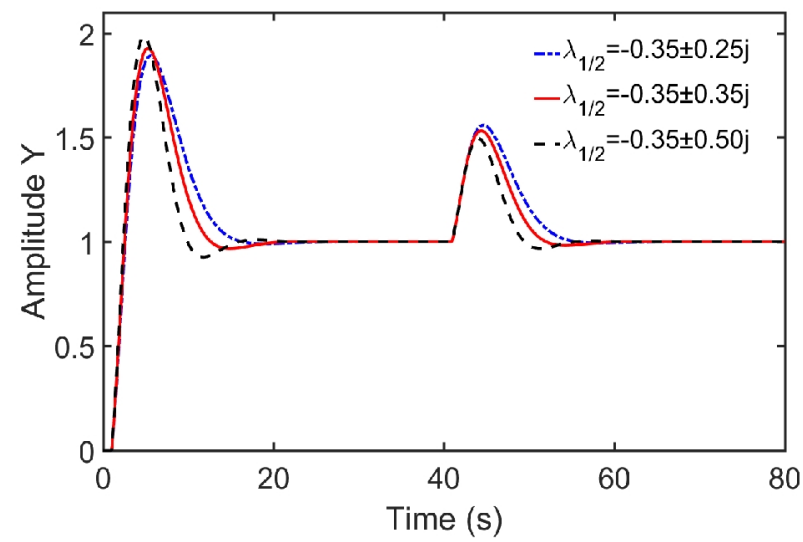

Fig. 4. Responses for a PI-control of the unstable first-order time delay process in the presence of the disturbance for different values of the imaginary part of desire pole.

The received parameters of the PI controller and the setpoint results, for the three desired pole with the same real, and with a different imaginary part, $\operatorname{Re}\{\lambda\}=-0.35 \operatorname{Im}\{\lambda\} \epsilon$ $(0.25 ; 0.35 ; 0.5)$ are shown in Table I, while the Load 
disturbance results have been presented in Table II.

TABLE I. RESULTING PI CONTROLLER FOR $R E\{\Lambda\}=-0.35$,

\begin{tabular}{|c|c|c|c|c|c|}
\hline $\begin{array}{c}\text { Imag. } \\
\text { part of } \\
\text { the } \\
\text { pole } \\
\mathbf{I m}\{\lambda\}\end{array}$ & $\begin{array}{c}\text { Prop. } \\
\text { gain } \\
\boldsymbol{K} \boldsymbol{p}\end{array}$ & $\begin{array}{c}\text { Integ. } \\
\text { gain } \\
\boldsymbol{K} \boldsymbol{i}\end{array}$ & $\begin{array}{c}\text { IAE } \\
\text { of the } \\
\text { output }(\boldsymbol{y})\end{array}$ & $\begin{array}{c}\text { Total } \\
\text { variation } \\
\text { of the } \\
\text { input }(\boldsymbol{u})\end{array}$ & $\begin{array}{c}\text { Overshot } \\
\text { of the } \\
\text { output } \\
(\boldsymbol{y})\end{array}$ \\
\hline \pm 0.25 & 2.619 & 0.277 & 7.37 & 7.06 & 1.89 \\
\hline \pm 0.35 & 2.737 & 0.346 & 6.76 & 7.81 & 1.93 \\
\hline \pm 0.50 & 2.977 & 0.459 & 6.14 & 9.28 & 1.98 \\
\hline
\end{tabular}

TABLE II. RESULTING PI CONTROLLER FOR $R E\{\Lambda\}=-0.35$, LOAD DISTURBANCE.

\begin{tabular}{|c|c|c|c|c|c|}
\hline $\begin{array}{c}\text { Imag. } \\
\text { part of } \\
\text { the } \\
\text { pole } \\
\operatorname{Im}\{\lambda\}\end{array}$ & $\begin{array}{c}\text { Prop. } \\
\text { gain } \\
K p\end{array}$ & $\begin{array}{c}\text { Integ. } \\
\text { gain } \\
K i\end{array}$ & $\begin{array}{c}\text { IAE } \\
\text { of the } \\
\text { output }(y)\end{array}$ & $\begin{array}{c}\text { Total } \\
\text { variation } \\
\text { of the } \\
\text { input }(u)\end{array}$ & $\begin{array}{c}\text { Overshot } \\
\text { of the } \\
\text { output } \\
(y)\end{array}$ \\
\hline \pm 0.25 & 2.619 & 0.277 & 3.68 & 2.80 & 1.56 \\
\hline \pm 0.35 & 2.737 & 0.346 & 3.05 & 2.92 & 1.53 \\
\hline \pm 0.50 & 2.977 & 0.459 & 2.40 & 3.13 & 1.49 \\
\hline
\end{tabular}

From Table I and Table II, and from Fig. 4, it can be observed that for the constant real part of the desired pole, by increasing an imaginary part of the pole, a set-point overshoot rises, while the peak value of the output falls, which implies a better disturbance compensation.

The received PI controller parameters and the set-point results, with three desired poles with the same imaginary part $I_{m}\{\lambda\}= \pm 0.35$, and with a real part $R_{e}\{\lambda\} \in(0.2 ; 0.3$; $0.4)$, are shown in Table III, while Load disturbance findings are illustrated in Table IV, and the response in Fig. 5.

TABLE III. RESULTING PI CONTROLLER FOR $I M\{\Lambda\}=-0.35$,

\begin{tabular}{|c|c|c|c|c|c|}
\hline $\begin{array}{c}\text { Real } \\
\text { part of } \\
\text { the } \\
\text { pole } \\
\boldsymbol{R}\{\{\boldsymbol{\lambda}\}\end{array}$ & $\begin{array}{c}\text { Prop. } \\
\text { gain } \\
\boldsymbol{K} \boldsymbol{p}\end{array}$ & $\begin{array}{c}\text { Integ. } \\
\text { gain } \\
\boldsymbol{K} \boldsymbol{i}\end{array}$ & $\begin{array}{c}\text { IAE } \\
\text { of the } \\
\text { output } \\
(\boldsymbol{y})\end{array}$ & $\begin{array}{c}\text { Total } \\
\text { variation } \\
\text { of the } \\
\text { input }(\boldsymbol{u})\end{array}$ & $\begin{array}{c}\text { Overshot } \\
\text { of the } \\
\text { output } \\
\boldsymbol{( y )}\end{array}$ \\
\hline \pm 0.2 & 2.478 & 0.364 & 8.24 & 8.40 & 2.00 \\
\hline \pm 0.3 & 2.684 & 0.354 & 7.00 & 7.94 & 1.94 \\
\hline \pm 0.4 & 2.763 & 0.333 & 6.68 & 7.66 & 1.91 \\
\hline
\end{tabular}

TABLE IV. RESULTING PI CONTROLLER FOR $I M\{\Lambda\}=-0.35$, LOAD DISTURBANCE.

\begin{tabular}{|c|c|c|c|c|c|}
\hline $\begin{array}{c}\text { Real } \\
\text { part of } \\
\text { the } \\
\text { pole } \\
\boldsymbol{R} \boldsymbol{R}\{\lambda\}\end{array}$ & $\begin{array}{c}\text { Prop. } \\
\text { gain }\end{array}$ & $\begin{array}{c}\text { Integ. } \\
\text { gain } \\
\boldsymbol{K} \boldsymbol{i}\end{array}$ & $\begin{array}{c}\text { IAE } \\
\text { of the } \\
\text { output } \\
(\boldsymbol{y})\end{array}$ & $\begin{array}{c}\text { Total } \\
\text { variation } \\
\text { of the } \\
\text { input }(\boldsymbol{u})\end{array}$ & $\begin{array}{c}\text { Overshot } \\
\text { of the } \\
\text { output } \\
(\boldsymbol{y})\end{array}$ \\
\hline \pm 0.25 & 2.478 & 0.364 & 3.76 & 3.38 & 1.57 \\
\hline \pm 0.35 & 2.684 & 0.354 & 3.15 & 3.01 & 1.54 \\
\hline \pm 0.50 & 2.763 & 0.333 & 3.06 & 2.85 & 1.53 \\
\hline
\end{tabular}

From Table III and Table IV, and from Fig. 5, which shows the response with the disturbance taking place in the same time and with the same amplitude level as in the previous example, it is clear that with bringing closer of the pole to the imaginary complex axis from the plane during the constant imaginary part of the pole, more negative characteristics, a greater overshoot and a worse disturbance compensation, are received, which is what IAE and TV indicate.

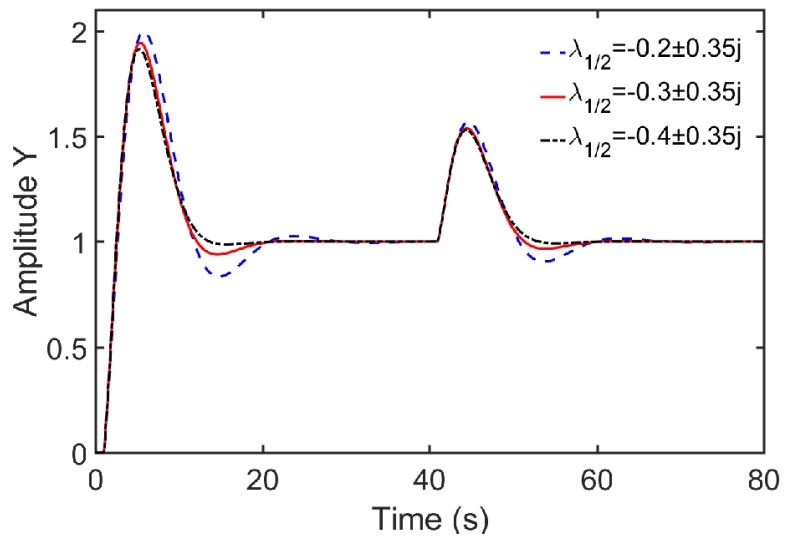

Fig. 5. Responses for a PI-control of the unstable first-order time delay process in the presence of the disturbance for different values of the real part of desire pole.

In case of the desired real poles, the boundary condition for their choice $-0.8<\lambda_{1}+\lambda_{2}<0$ is received by applying (23).

Set-point results for three different selections of the desired real poles and PI parameters are given in Table V, and Load disturbance results are revealed in Table VI.

\begin{tabular}{|c|c|c|c|c|c|}
\hline $\begin{array}{c}\text { Pole } \\
\{\lambda\}\end{array}$ & $\begin{array}{c}\text { Prop. } \\
\text { gain } \\
K p\end{array}$ & $\begin{array}{c}\text { Integ. } \\
\text { gain } \\
K i\end{array}$ & $\begin{array}{c}\text { IAE } \\
\text { of the } \\
\text { output } \\
(y)\end{array}$ & $\begin{array}{c}\text { Total } \\
\text { variation } \\
\text { of the } \\
\text { input }(u)\end{array}$ & $\begin{array}{l}\text { Overshot } \\
\text { of the } \\
\text { output } \\
(y)\end{array}$ \\
\hline $\begin{array}{l}-0.39 \\
-0.41\end{array}$ & 2.547 & 0.214 & 8.374 & 6.478 & 1.85 \\
\hline $\begin{array}{l}-0.3 \\
-0.4\end{array}$ & 2.488 & 0.191 & 8.997 & 6.257 & 1.84 \\
\hline $\begin{array}{l}-0.2 \\
-0.3\end{array}$ & 2.281 & 0.129 & 11.688 & 5.709 & 1.86 \\
\hline
\end{tabular}

TABLE VI. RESULTING PI CONTROLLER FOR REAL $\Lambda$, LOAD

\begin{tabular}{|c|c|c|c|c|c|}
\hline \multicolumn{6}{|c|}{ URBANCE. } \\
\hline $\begin{array}{c}\text { Pole } \\
\{\lambda\}\end{array}$ & $\begin{array}{c}\text { Prop. } \\
\text { gain } \\
K p\end{array}$ & $\begin{array}{c}\text { Integ. } \\
\text { gain } \\
K i\end{array}$ & $\begin{array}{c}\text { IAE } \\
\text { of the } \\
\text { output } \\
(y)\end{array}$ & $\begin{array}{c}\text { Total } \\
\text { variation } \\
\text { of the } \\
\text { input }(u)\end{array}$ & $\begin{array}{l}\text { Overshot } \\
\text { of the } \\
\text { output } \\
(y)\end{array}$ \\
\hline $\begin{array}{r}-0.39 \\
-0.41 \\
\end{array}$ & 2.547 & 0.214 & 4.66 & 2.70 & 1.58 \\
\hline $\begin{array}{l}-0.3 \\
-0.4\end{array}$ & 2.488 & 0.191 & 5.24 & 2.69 & 1.60 \\
\hline $\begin{array}{l}-0.2 \\
-0.3 \\
\end{array}$ & 2.281 & 0.129 & 7.76 & 2.70 & 1.67 \\
\hline
\end{tabular}

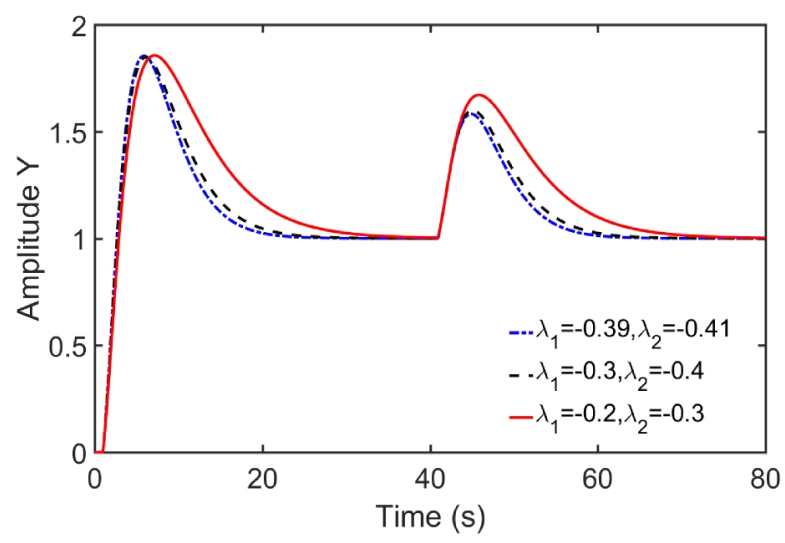

Fig. 6. Responses for a PI-control of the unstable first-order time delay process in the presence of the disturbance for the real part of desire pole. 
Responses of the unstable first-order time delay process under PI control where the set-point change is at $t=0$, load disturbance of magnitude 1 at $t=40$, is given in Fig. 6 .

Responses for a PI-control of the unstable first-order time delay process from Fig. 6, and the results from Table $\mathrm{V}$ and Table VI shows that in case of the selection of the real poles a longer settling time and much worse IAE of the output is received compared with the PI-control of the same process where controller parameters are received by choosing conjugate complex poles.

\section{B. Responses for a PI-Control of UFOPDT for Time Constant Filter Different Values}

The responses in Fig. 4, and Fig. 5 show that with PI controller application at UFOPTD is necessary to eliminate, i.e. reduce the overshoot for tracking a set point.

For selected poles $\lambda_{1 / 2}=-0.35 \pm 0.5 \mathrm{j}$, in Fig. 7 , the response of UFOPDT is illustrated regulated by the PI controller with and without the first-order filter (28). By increasing the time constant of the filter, a minor overshoot is received, which is seen in Fig. 7.

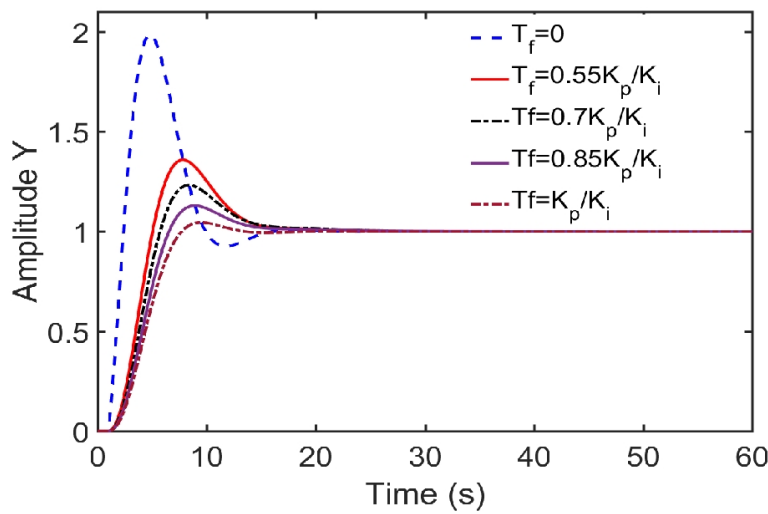

Fig. 7. Responses for a PI-control of the unstable first-order time delay process for different values of filter time constant.

\section{Confirmation of Boundary Conditions of the Imaginary} Part of the Pole

For a desired real part of the pole of the observed UFOPTD process, $\operatorname{Re}\{\lambda\}=-0.3$ by applying (18) boundary conditions for the imaginary part of the desired pole $I_{m}\{\lambda\}=$ 1.16556 is received.

The received controller parameters, in case when the imaginary part of the desired pole is greater or smaller for 5 percent than a boundary condition, are given in Table VII, and the response is shown in Fig. 8.

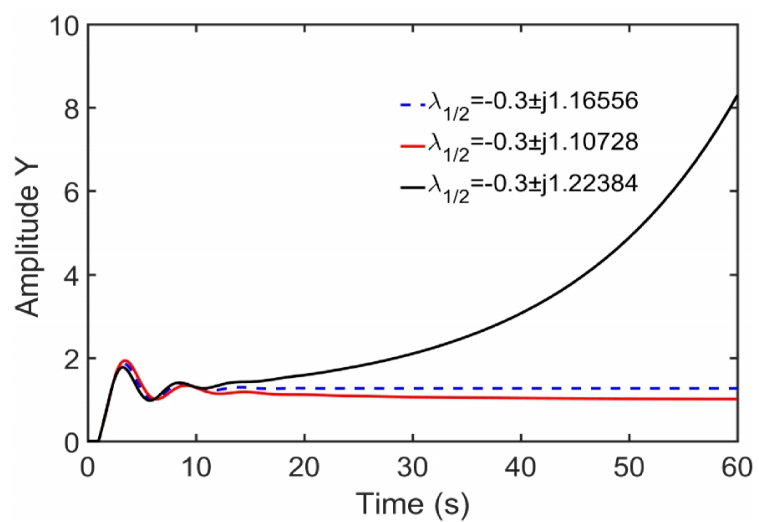

Fig. 8. Responses for a PI-control of the unstable first-order time delay process for different values of desired pole.
TABLE VII. PI CONTROLLER SETTINGS FOR THE PROPOSED

\begin{tabular}{|c|c|c|}
\hline $\begin{array}{c}\text { Desired pole } \\
\lambda 1 / 2\end{array}$ & $\begin{array}{c}\text { Proportional } \\
\text { gain } \boldsymbol{K} \boldsymbol{p}\end{array}$ & $\begin{array}{c}\text { Integral } \\
\text { gain } \boldsymbol{K} \boldsymbol{i}\end{array}$ \\
\hline$-0.3 \pm 1.10728 \mathrm{j}$ & 4.5447 & 0.2105 \\
\hline$-0.3 \pm 1.16556 \mathrm{j}$ & 4.6978 & $\sim 0$ \\
\hline$-0.3 \pm 1.22384 \mathrm{j}$ & 4.8438 & -0.2598 \\
\hline
\end{tabular}

The example shows that the boundary condition (18) for selection the imaginary part of the desired pole precisely specified. By increasing the imaginary part of the desired pole in comparison with the boundary condition, the system becomes unstable, and by reducing it, the system becomes stable.

If the imaginary part the same as the boundary condition from (18), the gain of the integral part of the PI controller is around zero, so UFOPDT is regulated only with the proportional amplifier. The system received in such a way is stable but it cannot reach the referential value. Reaching the referential value and the reduction of the overshoot can be achieved by adding the first-order filter:

$$
\left\{\begin{array}{l}
G_{f}(s)=\frac{K_{f}}{T_{f} s+1}, \\
T_{f}=n K_{p}, \\
K_{f}=\frac{K K_{p}-1}{K K_{p}},
\end{array}\right.
$$

which can be noticed in Fig. 9 .

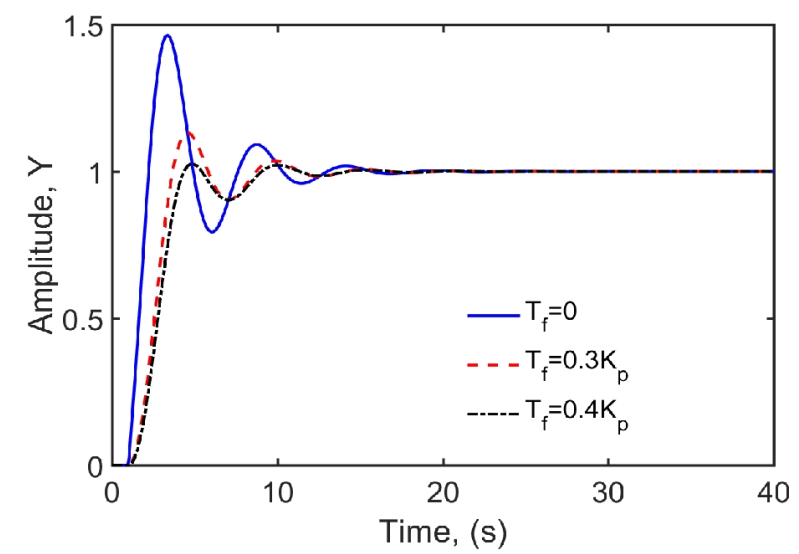

Fig. 9. Responses for a P-control of the unstable first-order time delay process for different values of the time constant filter.

\section{COMPARING THE RECEIVED RESUltS}

\section{A. Comparing the IPDT Processes Control}

\section{Example 1.}

In paper [8], the IPDT process has been demonstrated by using the transfer function

$$
G_{p}(s)=\frac{0.05}{s} e^{-5 s}
$$

for which, by using the proposed multiple dominant pole method, the received 2DOF PI controller are given in (32).

By selecting the desired poles in the given way by using the equation (24), $\lambda_{1 / 2}=-0.1 \pm 0.05 j, \quad$ is received 
wherefrom by replacing (25) and (26) the necessary gain of the PI controller, $K_{p}=1.9005$ and $K_{i}=0.0719$. By replacing the received values into the equation (27) the set-point filter transfer function is received:

$$
\begin{aligned}
& \left\{\begin{array}{l}
G_{c}(s)=1.84\left(1+\frac{1}{29.14 s}\right), \\
G_{f}(s)=\frac{b 29.14 s+1}{29.14 s+1}, \\
b=0.29,
\end{array}\right. \\
& \left\{\begin{array}{l}
G_{f}(s)=\frac{b 26.4367 s+1}{26.4366 s+1}, \\
b=0.4
\end{array}\right.
\end{aligned}
$$

Closed loop response of the system with or without the filter $(b=1)$, where 2DOF is the response received by using the method given in [8] and with PI the response received by using the proposed way of controller projection is shown in Fig. 10 wherefrom it can be clearly noticed that the response of the system regulated in the suggested way has considerably shorter settling time $\left(T_{s}=34 \mathrm{~s}\right)$ and the time of the increase $\left(T_{r}=19.7 \mathrm{~s}\right)$ compared with the method with which it has been compared $\left(T_{s}=53.4 \mathrm{~s} \mathrm{i} T_{r}=28.7 \mathrm{~s}\right)$.

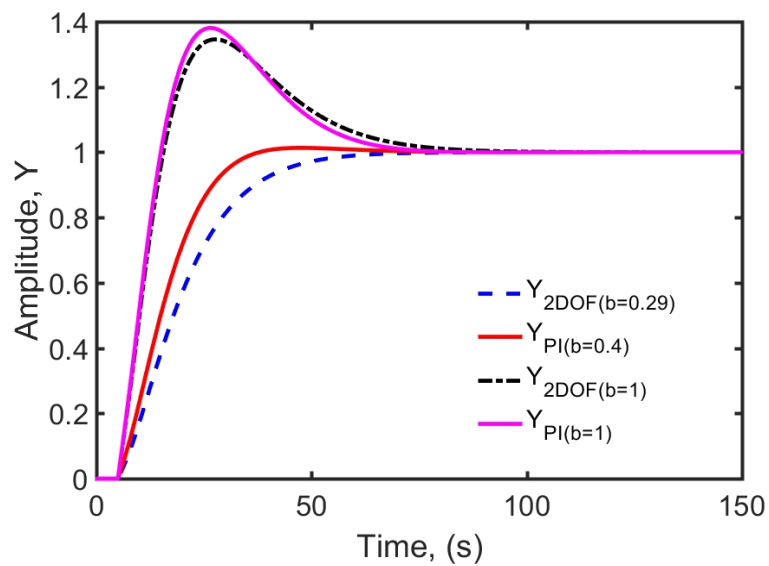

Fig. 10. Responses for a PI-control of IPDT plant with or without filter.

The response of both systems with the proposed controller parameters and the filters with disturbance which occurs at $t=150 \mathrm{~s}$ is given in Fig. 11 .

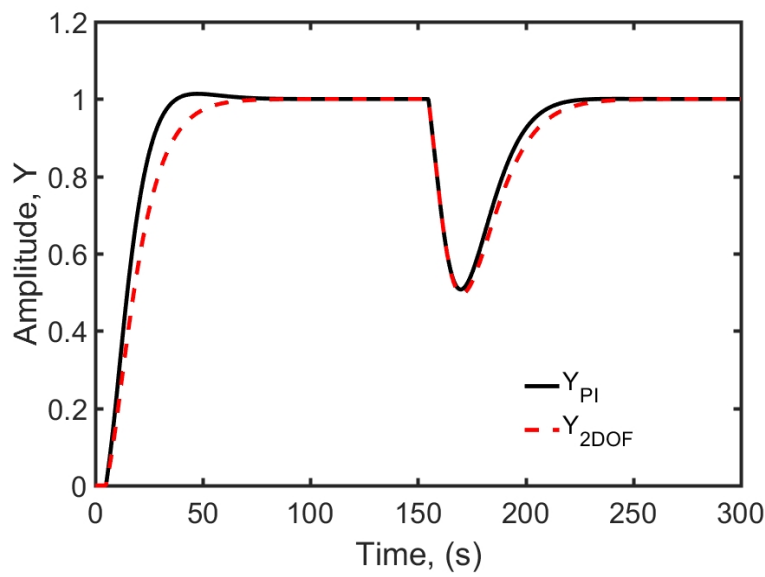

Fig. 11. Responses for a PI-control of IPDT plant in the presence of the disturbance.
In Table VIII, the values of the errors of the IAE and ISE for the set-point and load disturbance is given, wherefrom it can be deduced that the proposed method yields more optimal reaction to the disturbance effect.

TABLE VIII. VALUES OF IAE, ISE FOR SET-POINT AND LOAD DISTURBANCE.

\begin{tabular}{|c|c|c|c|c|}
\hline \multirow{2}{*}{ 2DOF PI controller } & \multicolumn{2}{|c|}{ Set-point } & \multicolumn{2}{c|}{ Load disturbance } \\
\cline { 2 - 5 } & IAE & ISE & IAE & ISE \\
\hline Proposed method & 16.492 & 14.296 & 15.837 & 5.541 \\
\hline
\end{tabular}

\section{Example 2.}

In paper [9], a comprehensive analysis of different PI controllers for IPDT processes, inter alia, for

$$
G_{p}(s)=\frac{1}{s} e^{-s} .
$$

For which, by using the triple real dominant pole (TRDP) method 2DOF PI controller are received:

$$
\left\{\begin{array}{l}
G_{c}(s)=0.461\left(1+\frac{1}{5.828 s}\right) \\
G_{f}(s)=\frac{b 5.828 s+1}{5.828 s+1} \\
b=0.293
\end{array}\right.
$$

By applying (24)-(26) onto the above-mentioned way the PI controller parameters are received as well as by using the proposed method to receive the following parameters:

$$
\left\{\begin{array}{l}
G_{c}(s)=0.4751+\frac{0.0899}{s}, \\
G_{f}(s)=\frac{b 5.2873 s+1}{5.2873 s+1}, \\
b=0.4 .
\end{array}\right.
$$

The system response onto which the disturbance of the amplitude at $t=20 \mathrm{~s}$ is shown in Fig. 12, while the error values of IAE, ISE for the set-point and load disturbance are given in Table IX.

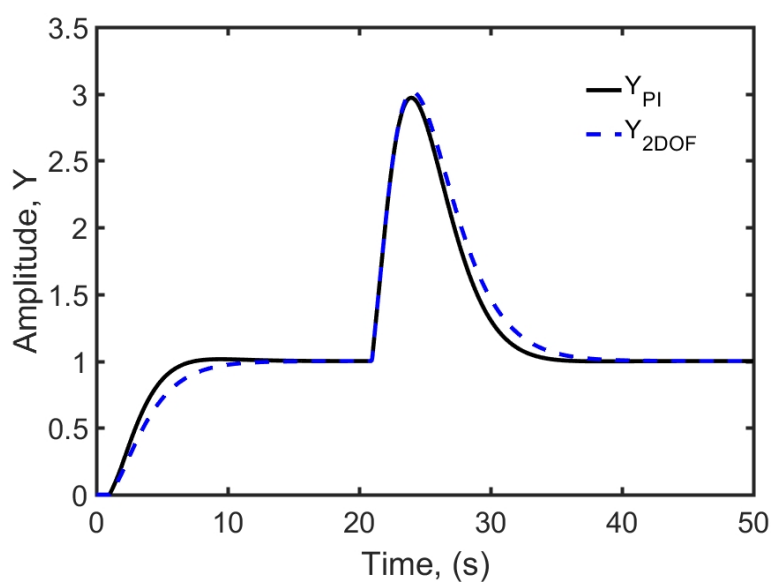

Fig. 12. Responses for a PI-control of IPDT plant in the presence of the disturbance. 
TABLE IX. VALUES OF IAE, ISE FOR SET-POINT AND LOAD DISTURBANCE.

\begin{tabular}{|c|c|c|c|c|}
\hline \multirow{2}{*}{} & \multicolumn{2}{|c|}{ Set-point } & \multicolumn{2}{c|}{$\begin{array}{c}\text { Load } \\
\text { disturbance }\end{array}$} \\
\cline { 2 - 5 } & IAE & ISE & IAE & ISE \\
\hline 2DOF PI controller & 4.120 & 2.850 & 12.642 & 17.656 \\
\hline Proposed method & 3.302 & 2.405 & 11.144 & 15.576 \\
\hline
\end{tabular}

In paper [9] the analysis is conducted of seven different PI controllers for IPDT plant observed transfer functions with responses given in image 6 and 7 (pp. 509), and the Performance measures of particular controllers given in Table (pp. 508).

By comparing the results given in [9], with the proposed method of projecting the PI, it can be clearly deduced that the proposed way yields the most optimal results in terms of the set-point of the IAE, more optimal IAE for load disturbance from the methods TRDP, SIMC1, AMIGO and MaShe.

\section{B. Comparing the Control of the UFOPTD Processes}

\section{Example 3.}

In paper [11] pp. 425, the UFOPTD process of the transfer function has been considered

$$
G_{p}(s)=\frac{1}{s-1} e^{-0.4 s}
$$

For which Majhi and Atherton projected a serial PI controller with $K_{p}=2.243, T_{i}=4.627$, and Ho et al. with $K_{p}=1.69, T_{i}=14.38$.

By using the boundary conditions (17) and (18), the desired poles have been selected at the proposed method of projecting the parallel PI controller $\lambda_{1 / 2}=-0.075 \pm 1.393 j$. By replacing (19) and (20) $K_{p}=1.7486, K_{i}=0.3419$ are received.

The responses for unit step input and for a step load disturbance of magnitude 0.5 are shown and compared in Fig. 13.

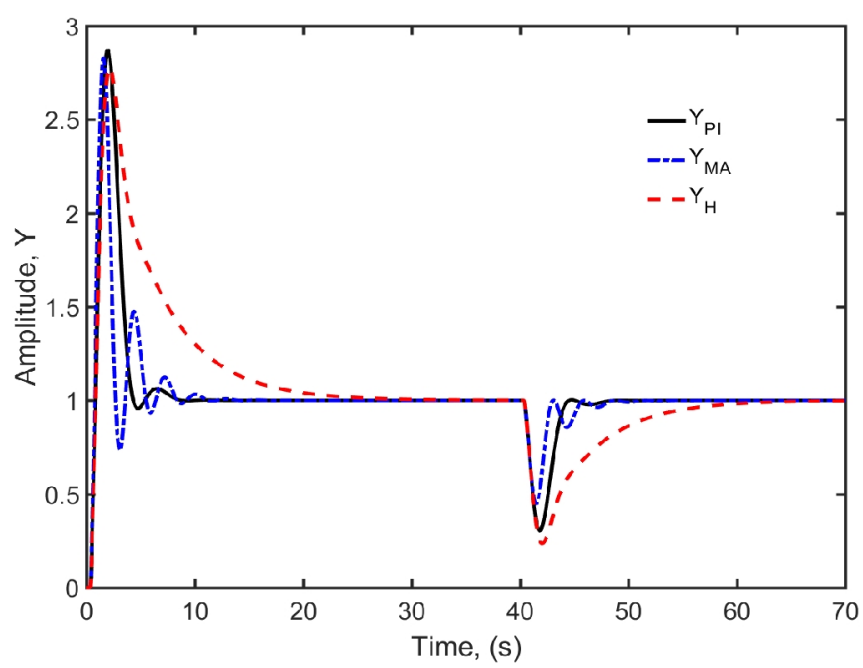

Fig. 13. Responses for a PI-control of UFOPDT plant in the presence of the disturbance.

The responses for a $+10 \%$ perturbation in the delay $\theta$ and in the process gain $K$ are shown in Fig. 14.

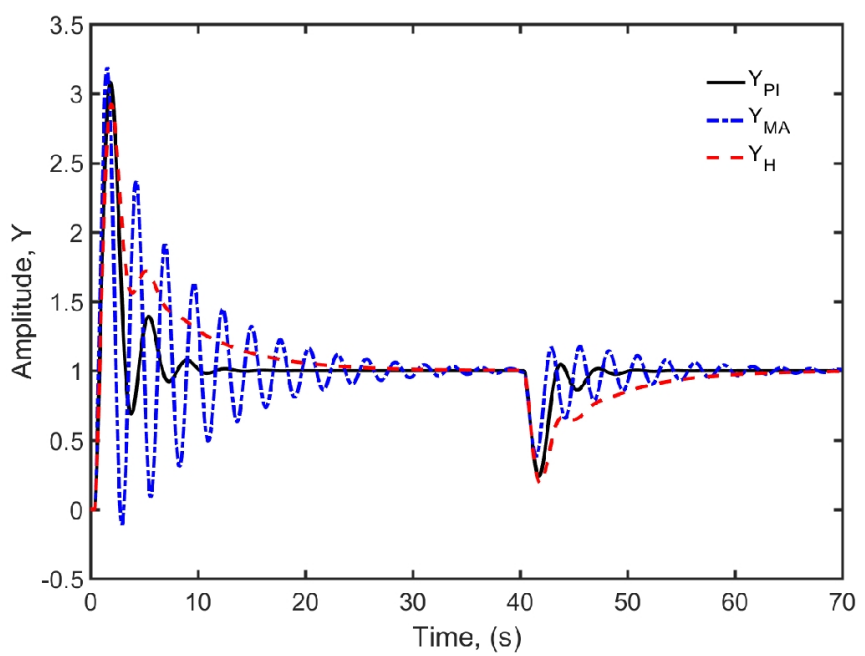

Fig. 14. Robust responses for PI-control of UFOPDT plant.

It can be concluded that the proposed method yields better results even in when there are uncertain changes shown by applying perturbation of $10 \%$ in the UFOPTD process parameters.

\section{CONCLUSIONS}

The proposed method of setting the PI controller for IPDT and UFOPTD processes turned out to be extremely simple to apply and efficient while using the boundary conditions for selecting the conjugate complex poles. The efficiency of the method is practically reflected in more optimal performances, i.e. the lower IAE and ISE index for the setpoint and load disturbance, and better robustness onto the unknown process parameter changes which had been examined for the $10 \%$ time delay change, compared with the 2DOF PI and serial PI controller.

\section{REFERENCES}

[1] K. J. Astrom, T. Hagglund, PID Controllers: Theory, Design, and Tuning. Instrument Society of America, Research Triangle Park, North Carolina, 1995.

[2] K. J. Astrom, T. Hagglund, "Revisiting the ziegler-nichols step response method for PID control", Journal of Process Control, vol. 14, no. 6, pp. 635-65, 2004. DOI: 10.1016/j.jprocont.2004.01.002.

[3] G. J. Silva, A. Datta, S. P. Bhattacharyya, PID controllers for TimeDelay Systems. Control Engineering, Birkhauser, Boston, 2005.

[4] V. Pockevicius, M. Cepenas, D. Miklusis, V. Markevičius, L. Zabuliene, D. Navikas, A. Valinevičius, D. Andriukaitis, "Feasibility research of non-invasive methods for interstitial fluid level measurement", Bio-Medical Materials and Engineering, vol. 28, iss. 2, pp. 601-612. 2017. DOI: 10.3233/BME-171699.

[5] S. Skogestad, "Simple analytic rules for model reduction and PID controller tuning", Journal of Process Control, vol. 13, no. 4, pp. 291-309, 2003. DOI: 10.1016/ S0959-1524(02)00062-8.

[6] R. Gerov, Z. Jovanovic, "Synthesis of the proportional integral controller for a minimum phase high order system by using the Lambert W function", IEEE 15th Int. Symposium on Intelligent Systems and Informatics (SISY 2017), 2017, pp. 169-174 DOI: 10.1109/SISY.2017.8080546

[7] M. Shamsuzzoha, S. Skogestad, "On-line PI controller tuning using closed-loop setpoint response", Journal of Process Control, vol. 20, no. 10 , pp. $1220-1234$, 2010. DOI: 10.3182/20100705-3-BE2011.00085 .

[8] M. Viteckova, A. Vitecek, "Two-degree of freedom controller tuning for integral plus time delay plants", ICIC Express Letters, vol. 2, no. 3, pp. 225-229, 2008.

[9] M. Huba, "Performance measures, performance limits and optimal PI control for the IPDT plant", Journal of Process Control, vol. 23, no. 4, pp. 500-515, 2013. DOI: 10.1016/j.jprocont.2013.01.002. 
[10] M. Huba, "Filter choice for an effective measurement noise attenuation in PI and PID controllers", IEEE Int. Conf. Mechatronics (ICM 2015), 2015, pp. 46-51. DOI: 10.1109/ICMECH.2015.7083946.

[11] S. Majhi, D. P. Atherton, "On-Line tuning of controllers for unstable FOPTD processes", IEEE Proc. Control Theory and Applications, vol. 147, no. 4, 2000, pp. 421-427. DOI: 10.1049/ip-cta:20000245.

[12] A. V. N. L. Anusha, A. S. Rao, "Design and analysis of IMC based PID controller for unstable systems for enhanced closed loop performance", IFAC Proceedings Volumes, vol. 45, no. 3, pp. 41-46, 2012. DOI: 10.3182/20120328-3-IT-3014.00007.

[13] R. Padma, M. N. Srinivas, M. Chidambaram, "A simple method of tuning PID controllers for stable and unstable FOPTD systems", Computers and Chemical Engineering, vol. 28, no. 11, pp. 22012218, 2004. DOI: 10.1016/j.compchemeng.2004.04.004.

[14] R. Corless, G. Gonnet, D. Hare, D. Jeffrey, D. Knuth, "On the Lambert W function", Advances in Computational Mathematics, vol. 5, pp. 329-359, 1996. DOI: 10.1007/BF02124750.

[15] S. Yi, P. W. Nelson, A. G. Ulsoy, "Analysis and control of time delayed systems via the Lambert W function", IFAC Proceedings Volumes, vol. 41, no. 2, pp. 13414-13419, 2008. DOI: 10.3182/20080706-5-KR-1001.02272.

[16] S. Yi, P. W. Nelson, A. G. Ulsoy, "Eigenvalue assignment via the Lambert W function for control of time-delay systems", Journal of Vibration and Control, vol. 16, no. 7-8, pp. 961-982, 2010. DOI: 10.1177/1077546309341102.

[17] S. Yi, S. Duan, P. W. Nelson, A. G. Ulsoy, "The Lambert W function approach to time delay systems and the LambertWDDE toolbox", IFAC Proceedings Volumes, vol. 45, no. 14, pp. 114-119, 2012. DOI: $10.3182 / 20120622-3-$ US-4021.00008.

[18] R. C. Gomez, W. Michiels, "Some special cases in the stability analysis of multi-dimensional time-delay systems using the matrix Lambert W function", Automatica, vol. 53, pp. 339-345, 2015. DOI: 10.1016/j.automatica. 2015.01.016. 